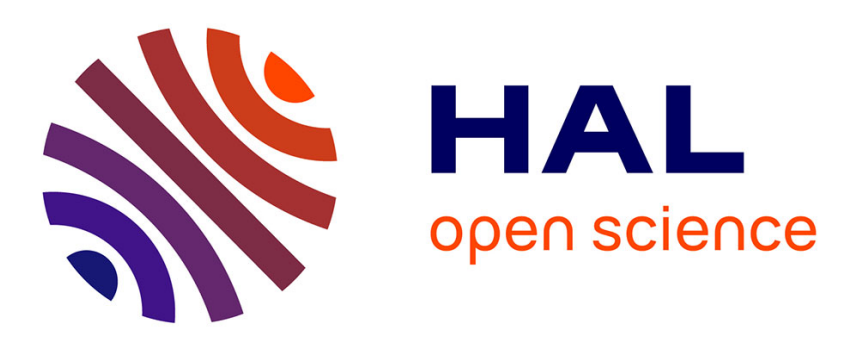

\title{
Anisotropy of thermal expansion in YAlO3 and NdGaO3
}

Odette Chaix-Pluchery, Bernard Chenevier, J. J. Robles

\section{To cite this version:}

Odette Chaix-Pluchery, Bernard Chenevier, J. J. Robles. Anisotropy of thermal expansion in YAlO3 and NdGaO3. Applied Physics Letters, 2005, 86, pp.251911. 10.1063/1.1944901 . hal-00207926

\section{HAL Id: hal-00207926 \\ https://hal.science/hal-00207926}

Submitted on 18 Jan 2008

HAL is a multi-disciplinary open access archive for the deposit and dissemination of scientific research documents, whether they are published or not. The documents may come from teaching and research institutions in France or abroad, or from public or private research centers.
L'archive ouverte pluridisciplinaire HAL, est destinée au dépôt et à la diffusion de documents scientifiques de niveau recherche, publiés ou non, émanant des établissements d'enseignement et de recherche français ou étrangers, des laboratoires publics ou privés. 


\title{
Anisotropy of thermal expansion in $\mathrm{YAlO}_{3}$ and $\mathrm{NdGaO}_{3}$
}

\author{
O. Chaix-Pluchery*, B. Chenevier, J. J. Robles \\ Laboratoire des Matériaux et du Génie Physique (CNRS UMR 5628), \\ ENSPG- INPG, BP 46, Saint-Martin d'Hères Cedex, F-38402, France
}

* Author to whom correspondence should be addressed; e-mail: Odette.Chaix@inpg.fr

Abstract:

$\mathrm{YAlO}_{3}$ and $\mathrm{NdGaO}_{3}$ thermal expansion coefficients were measured using in-situ powder Xray diffraction in the temperature range $28-650^{\circ} \mathrm{C}$. They exhibit a clear anisotropy: the expansion, quite similar along the [100] and [001] directions, is much lower along the [010] direction. The formation of cracks observed in $\mathrm{YBa}_{2} \mathrm{Cu}_{3} \mathrm{O}_{7-\delta}$ thin films deposited on $\mathrm{YAlO}_{3}$ and $\mathrm{NdGaO}_{3}$ substrates is likely related to the anisotropy. Stress value calculations have been performed in both systems. They indicate the intrinsic components are specifically high in $\mathrm{YAlO}_{3}$. 
Selecting a substrate for high $\mathrm{T}_{\mathrm{c}}$ superconducting film deposition is of crucial importance since it determines the epitaxial relationships, microstructure and, therefore, physical properties of the film. In $\mathrm{YBa}_{2} \mathrm{Cu}_{3} \mathrm{O}_{7-\delta}(\mathrm{YBCO})$ films, twin boundaries play an important role in the electric transport properties and the twinning geometry is strongly influenced by the substrate. The twinning along the $[110]$ and $[1 \overline{1} 0]$ directions of YBCO appears as the material passes through the tetragonal to orthorhombic transition. In $\mathrm{YAlO}_{3}$ and $\mathrm{NdGaO}_{3}$ substrates, a particular twinning geometry has been shown: the twinning directions of c-axis oriented YBCO films align along a unique direction of the substrate (namely the [010] direction) in contrast to films deposited on conventional substrates such as $\mathrm{MgO}, \mathrm{LaAlO}_{3}, \mathrm{SrTiO}_{3}$ where the more usual bidirectional twinning is found ${ }^{1,2}$. The impact of this unidirectional twinning on the transport properties of YBCO films has been the subject of several studies ${ }^{2,3}$.

It appears, through different papers, that the alignment of twin boundaries is strongly correlated to the presence of microcracks in the films ${ }^{4-6}$. Cracks are distributed in an array of lines parallel to the substrate a-axis (i.e. propagating perpendicular to the direction of alignment of the twin boundaries), 5-10 $\mu \mathrm{m}$ apart from one another in the case of $\mathrm{YAlO}_{3}$ substrate, and sometimes more distant in the case of $\mathrm{NdGaO}_{3}{ }^{4,6}$. The sequence between events is not clearly established. In addition, $\mathrm{YAlO}_{3}$ thermal expansion coefficients along the three directions are not known accurately; values reported in literature are given in Table $\mathrm{I}$ and let us assume anisotropy in $\mathrm{YAlO}_{3}{ }^{9,10}$ and $\mathrm{NdGaO}_{3}{ }^{13,14}$ thermal expansion.

Lattice constant mismatch and differential thermal expansion between film and substrate are the most important factors contributing to stress in films supported on substrates. The YBCO unit 
cell diagonal in the $(a, b)$ plane $\left(1_{110}\right)$ aligns with the substrate b-axis. This specific orientation minimizes the lattice mismatch between $\mathrm{YBCO}$ film and substrate: it is close to $2.3 \%$ with $\mathrm{YAlO}_{3}$ and to $0.8-0.9 \%$ with $\mathrm{NdGaO}_{3}$ at room temperature (lattice parameters are given in Table II, YBCO $\left.1_{110}=\sqrt{ } \mathrm{a}^{2}+\mathrm{b}^{2}=0.54519 \mathrm{~nm}^{16}\right)$.

To test the possible anisotropy in the thermal expansion of $\mathrm{YAlO}_{3}$ and $\mathrm{NdGaO}_{3}$ which could explain the formation of cracks in the thin films, accurate $\mathrm{YAlO}_{3}$ and $\mathrm{NdGaO}_{3}$ thermal expansion coefficients are needed. They will thus make possible to estimate the thermoelastic component of the residual stress in both systems. It was the goal of this study. A particularly well-adapted technique to obtain such accurate coefficients is the in-situ high temperature powder X-ray diffraction which permits one to collect reflections from various directions of the reciprocal space as a function of temperature and thus to obtain thermal expansion coefficients as a function of the orientation in the unit-cell.

Fine $\mathrm{YAlO}_{3}$ and $\mathrm{NdGaO}_{3}$ powder samples were obtained by grinding a small piece of a single crystal substrate. Samples were then annealed for several hours at $800^{\circ} \mathrm{C}$ to relax grinding-induced strains. To measure thermal expansion, the samples were progressively heated from room temperature up to $650^{\circ} \mathrm{C}$ by applying repeated sequences of temperature ramps followed by stabilisation using a high-temperature diffraction stage. Specifications of the heating stage are given in Ref. 23. The typical temperature range between two stabilisations was $50^{\circ} \mathrm{C}$. Diffraction patterns were recorded for $800 \mathrm{~s}$ at each stabilisation step. The angular position of carefully selected reflections was determined which permitted the lattice parameters to be refined at each annealing temperature. The values thus obtained at $28^{\circ} \mathrm{C}$ are given in Table II. The results were plotted as a function of temperature and fitted with a simple linear model of thermal expansion. The number of 
reflections selected at each temperature was 16 or 17 in the case of $\mathrm{YAlO}_{3}$, and varied between 5 and 13 for $\mathrm{NdGaO}_{3}$.

The thermal dependence of $\mathrm{YAlO}_{3}$ and $\mathrm{NdGaO}_{3}$ lattice parameters is shown in Figs. 1 and 2. A clear anisotropy of thermal expansion in both compounds is observed: expansion is clearly weaker along the [010] direction. The resulting thermal expansion coefficients along the three directions were found to be:

$$
\begin{gathered}
\alpha_{\mathrm{a}}=8.9( \pm 0.4) \times 10^{-6} \mathrm{~K}^{-1}, \alpha_{\mathrm{b}}=3.8( \pm 0.2) \times 10^{-6} \mathrm{~K}^{-1}, \alpha_{\mathrm{c}}=8.5( \pm 0.3) \times 10^{-6} \mathrm{~K}^{-1} \text { in } \mathrm{YAlO}_{3} \\
\alpha_{\mathrm{a}}=11.3( \pm 0.8) \times 10^{-6} \mathrm{~K}^{-1}, \alpha_{\mathrm{b}}=2.3( \pm 0.5) \times 10^{-6} \mathrm{~K}^{-1}, \alpha_{\mathrm{c}}=9.1( \pm 0.8) \times 10^{-6} \mathrm{~K}^{-1} \text { in } \mathrm{NdGaO}_{3} .
\end{gathered}
$$

It clearly appears that thermal expansion is sharply anisotropic. $\mathrm{YAlO}_{3}: \mathrm{Er}^{3+}, \mathrm{NdGaO}_{3}$ and $\mathrm{LaGaO}_{3}$ thermal expansion coefficients reported in literature are also weaker along the [010] direction, as seen in Table I. However, $\mathrm{NdGaO}_{3} \alpha$ values are reported to be greater than ours.

All of these compounds crystallize in the orthorhombic distorted $\mathrm{GdFeO}_{3}$-type perovskite structure (space group Pbnm) 12, 15, 18, 19, 21, 22. This structure is also described as pseudocubic and can be represented as a grid of $\left[\mathrm{AlO}_{6}\right]$ or $\left[\mathrm{GaO}_{6}\right]$ octahedra tilted around the [001], [110] and [111] pseudo-cubic axes (tilt angles equal to $9.46^{\circ}, 13.45^{\circ}$ and $16.39^{\circ}$ in $\mathrm{NdGaO}_{3}{ }^{25}$; to $9.32^{\circ}, 13.65^{\circ}$ and $16.48^{\circ}$ in $\mathrm{YAlO}_{3}{ }^{19}$, respectively). The $\mathrm{Y}$ and $\mathrm{Nd}$ atoms occupy hollows situated between octahedra.

Some peculiarities concerning the thermal behaviour of the b-axis lattice parameter at low temperature also occur in such compounds: anomalies at $50 \mathrm{~K}$ and $200 \mathrm{~K}$ in $\mathrm{NdGaO}_{3}$, negative thermal expansion in $\mathrm{PrGaO}_{3}$ at temperatures below $200 \mathrm{~K}{ }^{26}$. They have been related to rotational vibrations of the shared anion octahedra which have a negative contribution to the thermal expansion. The balance between rotations and distorsions of oxygen octahedra will depend on details of the crystal structure, in particular, on interactions between crystal vibrations and electronic 
excitations of rare earth cations. The thermal expansion anisotropy observed at high temperature in $\mathrm{YAlO}_{3}$ and $\mathrm{NdGaO}_{3}$ (in $\mathrm{LaGaO}_{3}$ also) cannot be explained by such interactions because of the absence of such ions with $4 \mathrm{f}$ electrons in the case of $\mathrm{YAlO}_{3}$ and $\mathrm{LaGaO}_{3}$.

A careful analysis of the crystal structures indicates no significant difference in the nearestneighbour interactions along a and b directions. The origin of the sharp difference detected between $\alpha_{a}$ and $\alpha_{b}$ remains unclear for the moment. Possible influence of next nearest-neighbours has to be considered.

To understand the development of residual stress at the $\mathrm{YBCO} / \mathrm{YAlO}_{3}\left(\mathrm{NdGaO}_{3}\right)$ interface, a $\sigma$ analysis in terms of intrinsic and thermoelastic stress has been made. As YBCO films are deposited on (001) substrates, the anisotropy in the thermal expansion coefficients is certainly important.

The thermal dependence of $\mathrm{YBCO} 1_{110}$ is also reported in Fig. 2 for comparison with $b$ parameters of both substrates. The very close values of $\mathrm{b}_{\mathrm{NdGaO} 3}$ and $\mathrm{YBCO} 1_{110}$ at a temperature close to $\mathrm{YBCO}$ deposition temperature $\left(818^{\circ} \mathrm{C}\right)$ make the strains very low whereas they are much larger in the case of $\mathrm{YAlO}_{3}$ substrate. An anisotropic biaxial stress model is considered $\left(\sigma=\sigma_{\text {int }}+\sigma_{\text {therm }}\right)$.

The direction dependent thermoelastic components are expressed as $\varepsilon_{\mathrm{ii}}=\frac{1}{\mathrm{E}} \sigma_{\mathrm{ii}}-\frac{v}{\mathrm{E}} \sigma_{\mathrm{jj}}=$ $\Delta \alpha_{\imath} \times \Delta \mathrm{T}(\mathrm{i}, \mathrm{j}=1,2$ and $\mathrm{i} \neq \mathrm{j})$. Here, $\mathrm{E}$ and $v$ are YBCO Young's modulus and Poisson's ratio, respectively $\left(\mathrm{E}=157 \mathrm{GPa}^{11}, \nu=0.3^{27}\right), \Delta \alpha$ and $\Delta \mathrm{T}$ are the difference in thermal expansion coefficients between film and substrate and temperature change from deposition temperature and room temperature, respectively. Calculations led to:

$$
\begin{array}{lll}
\sigma_{11 \text { therm }}=0.109 \mathrm{GPa} & \sigma_{22 \text { therm }}=0.966 \mathrm{GPa} & \text { in } \mathrm{NdGaO}_{3} \\
\sigma_{11 \text { therm }}=0.373 \mathrm{GPa} & \sigma_{22 \text { therm }}=0.860 \mathrm{GPa} & \text { in } \mathrm{YAlO}_{3}
\end{array}
$$


The formation of cracks propagating parallel to the substrate a-axis can be explained by the fact that $\sigma_{11 \text { therm }}$ value is much lower than $\sigma_{22 \text { therm }}$ value.

The direction dependent intrinsic $\sigma$ components have been also calculated $\left(\sigma_{\mathrm{int}}=\varepsilon_{/ /} \times \mathrm{E} /(1-\right.$ v)). We found:

$$
\begin{array}{lll}
\sigma_{11 \text { int }}=-1.57 \mathrm{GPa} & \sigma_{22 \text { int }}=-0.25 \mathrm{GPa} & \text { in } \mathrm{NdGaO}_{3} \\
\sigma_{11 \text { int }}=-12.9 \mathrm{GPa} & \sigma_{22 \text { int }}=-7.3 \mathrm{GPa} & \text { in } \mathrm{YAlO}_{3}
\end{array}
$$

Clearly, the $\mathrm{YAlO}_{3}$ intrinsic components are high and likely accomodated by plastic relaxation via threading dislocations. This part should be further demonstrated by performing high resolution electron microscopy observations.

In conclusion, the careful analysis of $\mathrm{YAlO}_{3}$ and $\mathrm{NdGaO}_{3}$ thermal expansion gives evidence of a clear anisotropy. The much weaker contribution along the [010] direction likely facilitates the formation of cracks parallel to the a-axis. Such a sharp difference between $\alpha_{\mathrm{a}}$ and $\alpha_{\mathrm{b}}$ cannot be explained by simple structural considerations. As differential thermal expansion is higher along the [010] direction, thermoelastic energy stored during the cooling process is high and relaxation is needed. Then, cracks formed during relaxation necessarily propagate along the [100] direction. Stress value calculations performed in both systems indicate the intrinsic components in $\mathrm{YAlO}_{3}$ are high. Plastic accomodation is probably acting to relax the considerable amount of intrinsic stress incorporated during film formation. 


\section{$\underline{\text { References }}$}

1- C. Dubourdieu, J.P. Sénateur, O. Thomas, F. Weiss, B.P. Thrane, Appl. Phys. Lett. 69, 1942 (1996).

2- C. Villard, G. Koren, D. Cohen, E. Polturak, B. Thrane, D. Chateignier, Phys. Rev. Lett. 77, 3913 (1996).

3- A. Casaca, G. Bonfait, C. Dubourdieu, F. Weiss, J.P. Sénateur, Phys. Rev. B 59, 1538 (1999).

4- J.J. Robles, A. Bartasyte, H.P. Ng, A. Abrutis, F. Weiss, Physica C 400, 36 (2003).

5- H. Yamasaki, Y. Nakagawa, A. Sawa, H. Obara, K. Develos, Physica C 372-376, 1885 (2002).

6- G. Koren, E. Polturak, N. Levy, G. Deutscher, N.D. Zakharov, Appl. Phys. Lett. 73, 3763 (1998).

7- J. Kawashima, Y. Yamada, I. Hirabayashi, Physica C 306, 114 (1998).

8- A. Kulpa, A. C. D. Chaklader, G. Roemer, D. Li Williams, W. N. Hardy, Supercond. Sci. Technol. 3, 483 (1990).

9- M.J. Weber, M. Bass, K. Andringa, R.R. Monchamp, E. Comperchio, Appl. Phys. Lett. 15, 342 (1969).

10- Impex-Hightech data: www.impex-hightec.de

11- Y. Yamada, J. Kawashima, J.G. Wen, Y. Niiori, I. Hirabayashi, Jpn. J. Appl. Phys. 39, 1111 (2000).

12- S.B. Ubizskii, L.O. Vasylechko, D.I. Savytskii, A.O. Matkovskii, I.M. Syvorotka, Supercond. Sci. Technol. 7, 766 (1994).

13- F. Sandiumenge, C. Dubs, P. Görnert, S. Gali, J. Appl. Phys. 75, 5243 (1994).

14- A. Senyshyn, L. Vasylechko, M. Knapp, U. Bismayer, M. Berkowski, A. Matkovskii, J. Alloys Compd. 382, 84 (2004).

15- W. Marti, P. Fischer, F. Altorfer, H.J. Scheel, M. Tadin, J. Phys.: Condens. Matter 6, 127 (1994). 
16- J. D. Jorgensen, B. W. Veal, A. P. Paulikas, L. J. Nowicki, G. W. Crabtree, H. Claus, W. K. Kwok, Phys. Rev. B 41, 1863 (1990).

17- J. D. Jorgensen, M. A. Beno, D. G. Hinks, L. Soderholm, K. J. Volin, R. L. Hitterman, J. D. Grace, I. K. Schuller, Phys. Rev. B 36, 3608 (1987).

18- R. Diel, G. Brandt, Mat. Res. Bull. 10, 85 (1975).

19- N.L. Ross, Phase Trans. 58, 27 (1996).

20- S. Geller, Acta Crystallogr. 10, 243 (1957).

21- L. Vasylechko, A. Matkovskii, D. Savytskii, A. Suchocki, F. Wallrafen, J. Alloys Compd. 291, 57 (1999).

22- L. Vasylechko, L. Akselrud, W. Morgenroth, U. Bismayer, A. Matkovskii, D. Savytskii, J. Alloys Compd. 297, 46 (2000).

23- O. Chaix-Pluchery, B. Chenevier, I. Matko, J. P. Sénateur, J. Appl. Phys. 96, 361 (2004).

24- J.F. Nye, Physical Properties of Crystals (Clarendon, Oxford, U.K., 1985).

25- R.H. Mitchell, Perovskites: modern and ancient (Almaz Press, Thunder Bay, Ontario, Canada, 2002).

26- D. Savytskii, L. Vasylechko, A. Senyshyn, A. Matkovskii, C Bähtz, M. L. Sanjuan, U. Bismayer, M. Berkowski, Phys. Rev. B 68, 024101 (2003).

27- A. Goyal, W.C. Oliver, P.D. Funkenbusch, D.M. Kroeger, S.J. Burns, Physica C 183, 221 (1991). 


\section{Figure captions}

Fig. 1: Temperature dependence of a- and c-axis $\mathrm{YAlO}_{3}$ and $\mathrm{NdGaO}_{3}$ lattice parameters.

Fig. 2: Temperature dependence of b-axis $\mathrm{YAlO}_{3}$ and $\mathrm{NdGaO}_{3}$ lattice parameter, and of the $\mathrm{YBCO}$ unit cell diagonal in the $(a, b)$ plane $\left(l_{110}\right)$, calculated from the YBCO structural data and thermal expansion coefficients given in Table II and Table I, respectively (in orthorhombic system $\alpha_{110}=\left(\alpha_{a} a^{2}+\alpha_{b} b^{2}\right) /\left(a^{2}+b^{2}\right)$, from Ref. 24). The tetragonal to orthorhombic YBCO transition temperature, close to $700^{\circ} \mathrm{C}$, is displayed as a dotted line. 


\section{Table I}

Thermal expansion coefficients of $\mathrm{YBCO}, \mathrm{YAlO}_{3}, \mathrm{NdGaO}_{3}$ and $\mathrm{LaGaO}_{3}$ as reported in literature and from this study.

\begin{tabular}{|c|c|c|}
\hline Compound & $10^{6} \alpha(K)^{-1}$ & Source \\
\hline $\mathbf{Y B a}_{2} \mathrm{Cu}_{3} \mathbf{O}_{7-\delta}(\delta=0.08)$ & $\alpha_{\text {eff }}=13.4$ & Ref. 7 \\
\hline orthorhombic $(\delta=0.18)$ & $\boldsymbol{\alpha}_{\mathrm{a}}=11.0 ; \boldsymbol{\alpha}_{\mathrm{b}}=8.7 ; \boldsymbol{\alpha}_{\mathrm{c}}=13.8$ & Ref. 8 \\
\hline tetragonal $(\delta=0.68)$ & $\alpha_{a}=\alpha_{b}=11.0 ; \alpha_{c}=19.6$ & Ref. 8 \\
\hline $\mathbf{Y A l O}_{3}$ crystal & $\alpha_{b}=2.2$ at $25^{\circ} \mathrm{C}$ & Ref. 9 \\
\hline $\mathbf{Y A l O}_{3}$ powder & $\alpha_{a}=8.9 ; \alpha_{b}=3.8 ; \alpha_{c}=8.5$ & This study \\
\hline YAlO $_{3}: \mathbf{E r}^{3+}$ (YAP laser crystals) & $\boldsymbol{\alpha}_{\mathrm{a}}=9.5 ; \boldsymbol{\alpha}_{\mathrm{b}}=4.3 ; \boldsymbol{\alpha}_{\mathrm{c}}=10.8$ & Ref. 10 \\
\hline $\mathrm{NdGaO}_{3}(110)$ oriented film & $\alpha_{\mathrm{a}}=10.0$ & Ref. 11 \\
\hline $\mathbf{N d G a O}_{3}$ powder & $\alpha_{110}=8.9$ & Ref. 12 \\
\hline $\mathbf{N d G a O}_{3}$ powder & $\boldsymbol{\alpha}_{\mathrm{a}}=12.5 ; \boldsymbol{\alpha}_{\mathrm{b}}=4.2 ; \boldsymbol{\alpha}_{\mathrm{c}}=9.8$ & Ref. 13 \\
\hline $\mathbf{N d G a O}_{3}$ powder $^{\mathrm{a}}$ & $\boldsymbol{\alpha}_{\mathrm{a}}=11.7 ; \boldsymbol{\alpha}_{\mathrm{b}}=5.4 ; \boldsymbol{\alpha}_{\mathrm{c}}=11.2$ & Ref. 14 \\
\hline $\mathrm{NdGaO}_{3}$ powder & $\boldsymbol{\alpha}_{\mathrm{a}}=11.3 ; \boldsymbol{\alpha}_{\mathrm{b}}=2.3 ; \boldsymbol{\alpha}_{\mathrm{c}}=9.1$ & This study \\
\hline $\mathbf{L a G a O}_{3}$ powder & $\alpha_{a}=12.1 ; \alpha_{b}=9.7 ; \alpha_{c}=11.0$ & Ref. 15 \\
\hline
\end{tabular}

\footnotetext{
${ }^{a}$ The $\alpha$ coefficients were obtained from a linear fit of $\mathrm{NdGaO}_{3}$ structural parameters given in Table I in Ref. 14 as a function of temperature. This paper was published during the preparation of ours.
} 


\section{Table II}

Lattice parameter values of $\mathrm{YBCO}, \mathrm{YAlO}_{3}$ and $\mathrm{NdGaO}_{3}$ as reported in literature and from this study.

\begin{tabular}{|c|c|c|c|c|}
\hline & a $\left(10^{-1} \mathrm{~nm}\right)$ & b $\left(10^{-1} \mathrm{~nm}\right)$ & c $\left(10^{-1} \mathrm{~nm}\right)$ & Source \\
\hline \multicolumn{5}{|l|}{$\mathrm{YBa}_{2} \mathrm{Cu}_{3} \mathrm{O}_{7-\delta}$} \\
\hline orthorhombic $(\delta=0.07)$ & $3.8227(1)$ & $3.8872(2)$ & $11.6802(2)$ & Ref. 16 \\
\hline tetragonal $818^{\circ} \mathrm{C}(\delta=0.6)$ & $3.9018(1)$ & $3.9018(1)$ & $11.9403(5)$ & Ref. 17 \\
\hline \multicolumn{5}{|l|}{$\mathrm{YAIO}_{3}$} \\
\hline \multirow[t]{2}{*}{ a } & $5.180(2)$ & $5.330(2)$ & $7.375(2)$ & Ref. 18 \\
\hline & $5.1671(6)$ & $5.3148(8)$ & $7.3538(9)$ & Ref. 19 \\
\hline $\mathrm{b}$ & $5.179(2)$ & $5.327(1)$ & $7.373(2)$ & This study \\
\hline \multicolumn{5}{|l|}{$\mathrm{NdGaO}_{3}$} \\
\hline & 5.426 & 5.502 & 7.706 & Ref. 20 \\
\hline & $5.4276(1)$ & $5.4979(1)$ & $7.7078(2)$ & Refs. 12,21 , \\
\hline & & & & 22 \\
\hline $\mathrm{b}$ & $5.428(4)$ & $5.502(4)$ & $7.707(4)$ & This study \\
\hline
\end{tabular}

a Lattice parameters were converted to Pbnm space group from standardized Pnma space group in Ref. 18.

${ }^{\mathrm{b}}$ a, b, c refined values were obtained at $28^{\circ} \mathrm{C}$ from angular positions of the diffraction lines. 

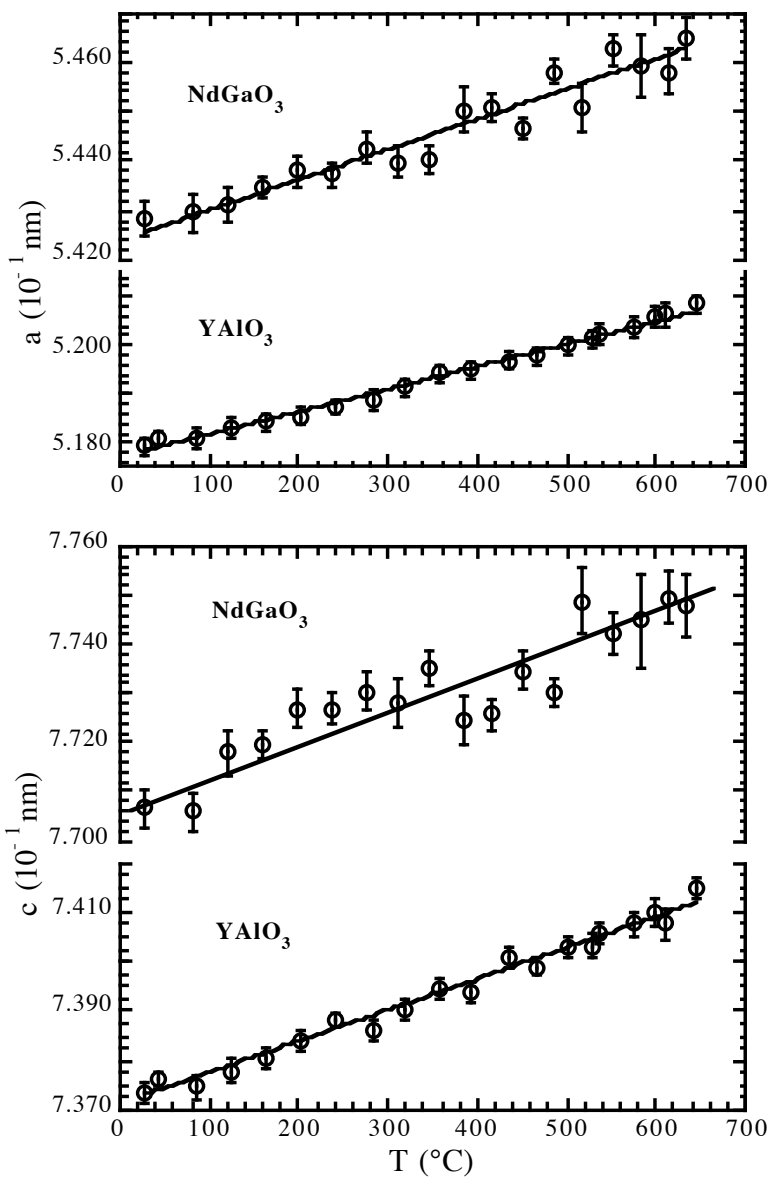

Fig. 1 


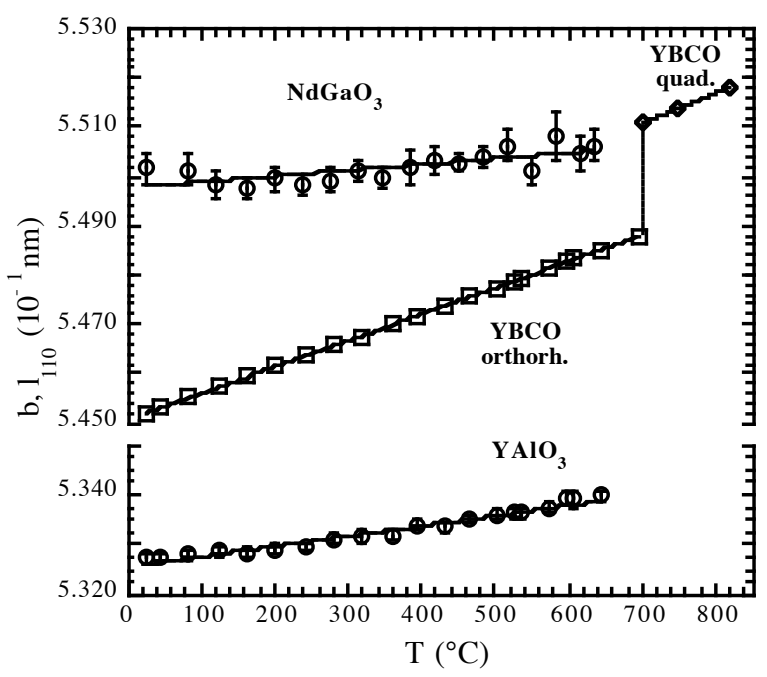

Fig. 2 